\title{
POLA CEDERA KASUS KEKERASAN FISIK PADA ANAK DI R. S. BHAYANGKARA MANADO PERIODE TAHUN 2013
}

\author{
Chriselya L. Janise \\ Erwin G. Kristanto \\ James F. Siwu
}

\author{
Bagian Forensik Kedokteran Forensik \& Medikolegal Fakultas Kedokteran \\ Universitas Sam Ratulangi - RSUP Prof. Dr. R. D. Kandou Manado \\ Email: croriwo11_285@yahoo.com
}

\begin{abstract}
Child abuse in Indonesia shows a tendency to increase every year.This study aimed to detect the injury patterns in the living victims due to child abuse. This was a descriptive retrospective study. Data were obtained from the 2013 medical records of Bhayangkara Hospital in Manado. Variables of this study were types of violence, types of injuries, and locations of injuries. The results showed that the types of violence were oppression (66\%) and sexual abuse (34\%). The most frequent type of injuries was bruise (53\%), followed by laceration (27\%) and excoriation (20\%). The location of injuries were mostly on the head (65\%), especially on the left eye (19\% of the head), followed by the other parts of the body. Conclusion: In this study, concerning child abuse, the most frequent type of violence was oppression. The most frequent type of injuries was bruise, and the location of injuries was mostly on the head, especially on the left eye.
\end{abstract}

Keywords: injury pattern, physical violence, children.

\begin{abstract}
Abstrak: Kekerasan pada anak di Indonesia memperlihatkan kecenderungan meningkat setiap tahun. Penelitian ini bertujuan untuk mendapatkan pola cedera pada anak (yang hidup) yang menjadi korban kekerasan. Penelitian ini menggunakan metode deskriptif retrospektif. Pengambilan data dilakukan di R.S. Bhayangkara Manado periode tahun 2013 dengan memanfaatkan data sekunder dari rekam medis orang hidup, jenis kekerasan yang paling sering terjadi pada kasus kekerasan anak, jenis cedera, dan letak cedera sebagai variabel penelitian. Hasil penelitian memperlihatkan jenis kekerasan yang ditemukan ialah penganiayaan (66\%) dan kekerasan seksual (34\%). Jenis cedera yang tersering ditemukan ialah memar (53\%), diikuti oleh luka robek (27\%) dan luka lecet (20\%). Lokasi cedera yang terbanyak di daerah kepala (65\%) terutama mata kiri (19\% dari bagian kepala), diikuti oleh bagian tubuh lainnya. Simpulan: Pada penelitian ini, jenis-jenis kekerasan yang tersering ditemukan pada anak berupa penganiayaan dengan jenis cedera tersering berupa memar. Lokasi cedera tersering pada daerah kepala, terutama mata kiri.
\end{abstract}

Kata kunci: pola cedera, kekerasan fisik, anak.

Kasus kekerasan pada anak cukup meresahkan masyarakat, karena semakin meningkatnya kasus-kasus tersebut setiap tahunnya. Kekerasan pada anak ini sangat memrihatinkan karena dari data yang didapat tiap tahunnya kekerasan pada anak terbanyak disebabkan oleh keluarganya sendiri yaitu orang tua korban (ibu dan ayah). Kekerasan tersebut dikenal dengan perlakuan salah pada anak atau child abuse yang merupakan bagian dari kekerasan dalam rumah tangga (domestic violence). ${ }^{1,2}$

Kekerasan pada anak tidak mudah untuk dikenali karena anak belum mampu untuk menyatakan sendiri keluhannya kepada dokter, terkait dengan kekerasan 
yang dialaminya. Kepekaan seorang dokter sangat dibutuhkan karena pada usianya seorang anak sering mendapat luka atau goresan-goresan yang terjadi secara tidak sengaja akibat aktifitas bermain. Masyarakat sering melewatkan penyebab sebenarnya dari luka atau goresan pada anak.

Adanya ketakutan pada diri anak, yang disebabkan oleh orang tua atau pengasuh dan juga faktor usia yang menyebabkan anak tersebut belum bisa berbicara, menjadi salah satu faktor yang menyebabkan sulitnya dokter untuk mengetahui apakah anak tersebut merupakan korban kekerasan atau bukan. Oleh karena itu, diperlukan metode-metode tertentu yang dapat membantu dokter untuk mendeteksinya. Dalam hal ini aspekaspek dari forensik klinik sangatlah berperan. ${ }^{3}$ Dokter harus bisa mengetahui keadaan psikologis dan keadaan fisik anak, apakah luka tersebut murni karena anak lalai dalam bermain atau karena tindak kekerasan yang dilakukan seseorang kepada anak tersebut.

Penelitian ini bertujuan untuk meningkatkan kemampuan deteksi kasus kekerasan pada anak dari para dokter melalui pola cedera kekerasan pada anak.

\section{METODE PENELITIAN}

Penelitian ini bersifat deskriptif retrospektif dengan menggunakan data sekunder. Penelitian dilaksanakan di Rumah Sakit Bhayangkara Manado. Sampel penelitian ini yaitu semua anak yang menjadi korban kekerasan fisik di Rumah Sakit Bhayangkara Manado periode tahun 2013 yang sesuai dengan kriteria inklusi. Kriteria inklusi pada penelitian ini ialah: ${ }^{4}$ anak laki-laki atau anak perempuan berusia dibawah 18 tahun dan pasien yang diterima di UGD Rumah Sakit Bhayangkara Manado, yang diminta visum et repertum korban hidup oleh pihak kepolisian. Sebagai kriteria eksklusi ialah usia anak yang tidak jelas dan diduga berusia melebihi usia batasan anak. Variabel penelitian ini ialah jenis kekerasan yang paling sering terjadi pada kasus kekerasan pada anak, jenis cedera, dan letak cedera.

\section{HASIL PENELITIAN}

Data dari Rumah Sakit Bhayangkara Manado periode tahun 2013 memperlihatkan 271 anak sebagai korban kekerasan fisik. Sampel penelitian yang memenuhi kriteria inklusi ialah 232 anak. Pada penelitian ini didapatkan usia terendah 1 tahun dan usia tertinggi 17 tahun. Rerata usia yang didapat 14,1 tahun dan usia yang paling banyak menjadi korban ialah 16 tahun.

Dari data yang didapat ternyata kasus kekerasan tertinggi pada anak terjadi di kota Manado (78\%) (Tabel 1).

Tabel 1. Kekerasan pada anak berdasarkan daerah tempat pelaporan

\begin{tabular}{lcc}
\hline Tempat kejadian & Jumlah & $\mathbf{\%}$ \\
\hline Manado & 180 & 78 \\
Minahasa & 33 & 14 \\
Minut & 14 & 6 \\
Tomohon & 1 & 0 \\
Minsel & 2 & 1 \\
Mitra & 2 & 1 \\
Total & 232 & 100 \\
\hline
\end{tabular}

Pada Tabel 2 terlihat bahwa berdasarkan jenis kekerasan pada anak yang tertinggi ialah penganiayaan (66\%).

Tabel 2. Jenis kekerasan pada anak

\begin{tabular}{lcc}
\hline Jenis kekerasan & Jumlah & \% \\
\hline Penganiayaan & 152 & 66 \\
Kekerasan seksual & 80 & 34 \\
Total & 232 & 100 \\
\hline
\end{tabular}

Tabel 3 memperlihatkan dari total kasus ternyata $16 \%$ dari korban kekerasan seksual pada anak didapatkan hamil. 
Tabel 3. Korban hamil pada kasus kekerasan seksual anak

\begin{tabular}{lcc}
\hline Anak perempuan & Jumlah & $\mathbf{\%}$ \\
\hline Hamil & 11 & 16 \\
Tidak hamil & 56 & 84 \\
Total & 67 & 100 \\
\hline
\end{tabular}

Data dari Tabel 4 memperlihatkan berdasarkan jenis cedera pada kasus kekerasan anak dari total kasus didapat yang tertinggi ialah memar (53\%).

Tabel 4. Jenis cedera pada kasus kekerasan anak

\begin{tabular}{lcc}
\hline Jenis cedera & Jumlah & \% \\
\hline Memar & 192 & 53 \\
Luka robek & 98 & 27 \\
Luka lecet & 75 & 20 \\
Total & 365 & 100 \\
\hline
\end{tabular}

Pada Tabel 5 terlihat bahwa berdasarkan jenis kelamin, anak perempuan (51\%) lebih banyak menjadi korban kekerasan daripada anak laki-laki (49\%).

Tabel 5. Korban kekerasan pada anak berdasarkan jenis kelamin

\begin{tabular}{lcc}
\hline Jenis Kelamin & Jumlah & \% \\
\hline Perempuan & 119 & 51 \\
Laki-laki & 113 & 49 \\
Total & 232 & 100 \\
\hline
\end{tabular}

Pada Tabel 6 terlihat bahwa berdasarkan cedera yang terjadi pada alat kelamin anak perempuan, korban kekerasan yang tertinggi terjadi di selaput dara (94\%).

Tabel 6. Cedera yang terjadi pada alat kelamin anak perempuan korban kekerasan

\begin{tabular}{lcc}
\hline Letak & Jumlah & $\mathbf{\%}$ \\
\hline Selaput dara & 77 & 94 \\
Labia mayora & 1 & 1 \\
Labia minora & 2 & 3 \\
Vagina & 2 & 2 \\
Total & 82 & 100 \\
\hline
\end{tabular}

Dari total kasus kekerasan yang didapat, ternyata cedera terbanyak terjadi di daerah kepala (65\%) (Gambar 1 dan Tabel 7).

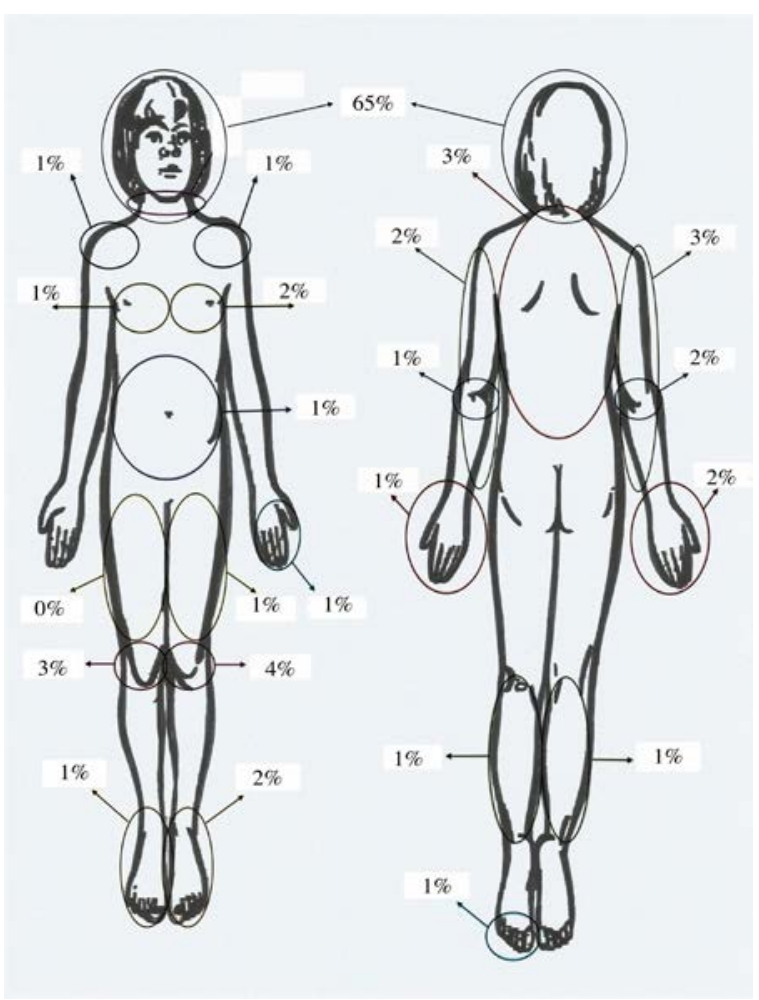

Gambar 1. Letak cedera akibat kekerasan pada tubuh anak dilihat dari dua sudut pandang (depan dan belakang).

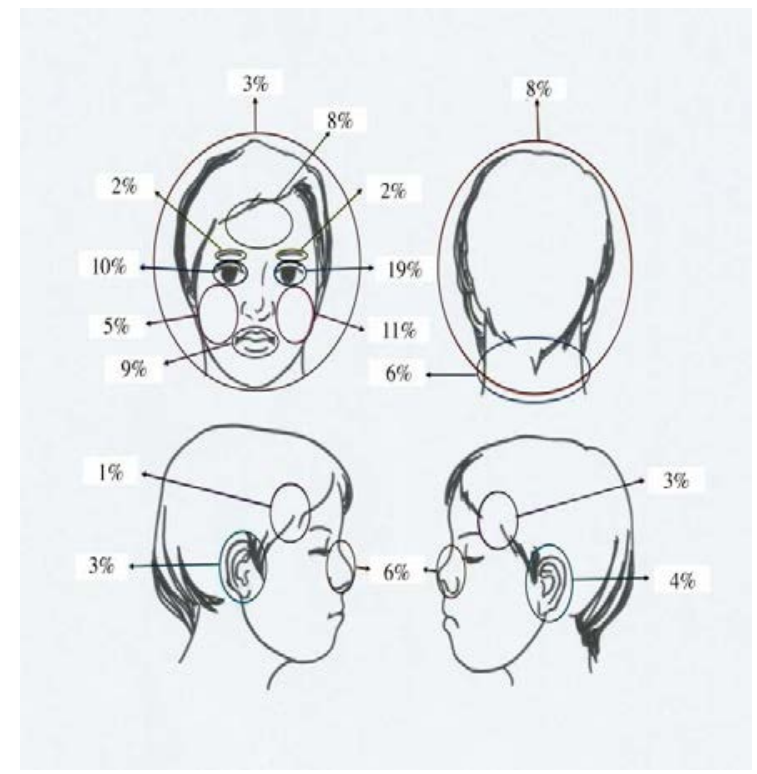

Gambar 2. Letak cedera pada kekerasan anak di bagian kepala dilihat dari empat sudut pandang (depan, belakang, samping kanan, dan samping kiri). 
Tabel 7. Letak cedera pada seluruh tubuh dilihat dari 2 sudut pandang

\begin{tabular}{lcc}
\hline Letak & Jumlah & $\mathbf{\%}$ \\
\hline Kepala & 237 & $\mathbf{6 5}$ \\
Bahu kiri & 5 & 1 \\
Bahu kanan & 5 & 1 \\
Punggung & 12 & 3 \\
Dada kiri & 6 & 2 \\
Dada kanan & 2 & 1 \\
Lengan kiri & 9 & 2 \\
Lengan kanan & 10 & 3 \\
Siku kiri & 4 & 1 \\
Siku kanan & 7 & 2 \\
Tangan kiri & 5 & 1 \\
Tangan kanan & 7 & 2 \\
Jari tangan & 4 & 1 \\
Jari kaki & 2 & 1 \\
Perut & 2 & 1 \\
Kaki kiri & 8 & 2 \\
Kaki kanan & 5 & 1 \\
Paha kiri & 4 & 1 \\
Paha kanan & 1 & 0 \\
Lutut kiri & 13 & 4 \\
Lutut kanan & 12 & 3 \\
Betis kiri & 2 & 1 \\
Betis kanan & 2 & 1 \\
Total & 364 & 100 \\
\hline
\end{tabular}

Dari total kasus kekerasan yang didapat, berdasarkan letak cedera kekerasan pada kepala anak ternyata terbanyak terjadi di bagian mata kiri (19\%) (Gambar 2).

\section{BAHASAN}

Kasus kekerasan pada anak jaman sekarang sudah merupakan hal yang banyak terjadi di masyarakat. Harian Metro 11 Maret 2015 memuat data yang diperoleh dari Pengadilan Negeri (PN) Tahuna bahwa sepanjang tahun 2014, 75\% perkara yang disidangkan merupakan kasus kekerasan seksual pada anak. Sebagian kasus ini sudah berkekuatan hukum tetap (in kracht), yang lainnya masih dalam proses peradilan. Hingga bulan Maret 2015, perkara yang dilimpahkan ke PN Tahuna juga didominasi oleh kasus jenis tersebut. Dari 13 kasus yang masuk, 6 di antaranya kasus pelecehan atau kekerasan seksual terhadap anak. $^{5}$ Pada penelitian ini didapatkan kekerasan pada anak di tahun 2013 sejumlah 271 kasus; 232 kasus yang memenuhi kriteria inklusi. Kejadian kekerasan pada anak setiap tahunnya mengalami peningkatan yang cukup untuk menjadi perhatian khusus, tidak hanya oleh orang tua, keluarga atau petugas yang berwenang seperti polisi melainkan juga oleh dokter selaku petugas yang membantu dalam proses penegakan hukum suatu kasus. Dengan kata lain, dokter akan mendeteksi dan menentukan apakah anak tersebut merupakan korban kekerasan atau tidak.

Data penelitian yang diperoleh dari Rumah Sakit Bhayangkara Manado memperlihatkan wilayah yang dilaporkan sebagai tempat terjadinya kekerasan pada anak ialah di provinsi Sulawesi Utara yang mencakup Manado, Minahasa, Minahasa Utara, Tomohon, Minahasa Selatan dan Minahasa Utara (Tabel 1). Persentase tertinggi terdapat di daerah Manado (180 kasus 78\%); hal ini mungkin disebabkan karena lokasi RS Bhayangkara terletak di kota Manado. Dari total kasus 271 orang anak, terdapat beberapa kasus yang berasal dari luar provinsi Sulawesi Utara tetapi tidak diikutsertakan dalam penelitian ini karena tidak memenuhi kriteria inklusi.

Dari hasil penelitian yang diperoleh korban terbanyak yang mengalami kasus kekerasan pada anak ialah perempuan (51\%) (Tabel 5). Hal ini serupa dengan angka kejadian kasus kekerasan terhadap anak yang terjadi di Malaysia. ${ }^{6}$

Berdasarkan jenis cedera yang terjadi, jenis cedera dapat berupa memar, luka robek dan luka lecet, dan jenis cedera tertinggi yaitu memar (53\%).

Kekerasan pada anak yang ditemukan berupa penganiayaan sebesar $66 \%$ dan kekerasan seksual sebesar 34\%. Anak-anak korban kekerasan seksual tidak hanya mendapatkan bekas pukulan tapi banyak juga yang menjadi hamil. Penggunaan atau pemanfaatan Kontrasepsi Darurat (Kondar) seperti: pil Progestrin 2x1 tablet, pil Estrogen 2x10 mg, Mifepristone 1x600 mg dan pil Danazol 2x4 tablet harus dipikirkan ketersediannya di Faskes primer atau sekunder, $^{7}$ mengingat angka kejadian 
kehamilan yang cukup tinggi pada kasus kekerasan seksual pada anak yaitu 16\% (Tabel 3).

Pada anak korban kekerasan ditemukan daerah-daerah yang sering mengalami cedera (Gambar 1, Tabel 7). Daerah kepala merupakan lokasi tersering (65\%). Dari bagian kepala, ternyata terbanyak terjadi di bagian mata kiri (19\%) (Gambar 2). Pada kasus kekerasan pada anak, pemeriksaan mata untuk deteksi cedera harus menjadi perhatian utama karena terbukti merupakan lokasi tersering terjadinya cedera baik berupa hifema dan katarak traumatik. ${ }^{8,9}$ Hal ini perlu diwaspadai agar tidak terlewatkan dalam pemeriksaan. Tingginya persentase cedera pada mata kiri dibandingkan mata kanan serta pipi kiri dibandingkan pipi kanan (sekitar 2 x lipat) mungkin disebabkan karena pelaku bertangan kanan. Hal ini sesuai dengan kenyataan bahwa populasi yang bertangan kanan lebih banyak daripada yang bertangan kidal. Kondisi ini dapat menjadi pertimbangan dalam penyidikan.

Cedera pada daerah kemaluan akibat kekerasan seksual pada anak ditemukan pada himen, labia mayora, labia minora, dan vagina, dengan cedera tertinggi terdapat pada himen (94\%). Selain berdampak terhadap fisik dan kejiwaan anak, cedera tersebut dapat berakibat terjadinya kehamilan yang tentunya merupakan hal yang sangat tidak diharapkan.

Efek kekerasan seksual terhadap anak antara lain depresi, ${ }^{10}$ gangguan stres pascatrauma, ${ }^{11}$ kegelisahan, ${ }^{12}$ kecenderungan untuk menjadi korban lebih lanjut pada masa dewasa, ${ }^{13}$ dan cedera untuk anak di antara masalah lainnya. ${ }^{14}$ Pelecehan seksual oleh anggota keluarga ialah bentuk inses, dan dapat menghasilkan dampak yang lebih serius dan trauma psikologis jangka panjang, terutama dalam kasus inses orang tua. ${ }^{15}$

Di Amerika Utara, sekitar 15-25\% perempuan dan 5-15\% laki-laki yang mengalami pelecehan seksual saat mereka masih anak-anak. ${ }^{16-18}$ Sebagian besar pelaku pelecehan seksual ialah orang yang dikenal oleh korban. Sekitar 30\% pelaku ialah keluarga dari si anak, paling sering saudara laki-laki, ayah, paman, atau sepupu. Sekitar $60 \%$ pelaku ialah kenalan lainnya seperti teman dari keluarga, pengasuh, atau tetangga. Orang asing sebagai pelaku hanya sekitar $10 \%$ dalam kasus penyalahgunaan seksual anak, ${ }^{16}$ dan umumnya pelecehan seksual anak dilakukan oleh laki-laki. ${ }^{17-19}$

\section{SIMPULAN}

Berdasarkan hasil penelitian mengenai pola cedera kekerasan fisik pada anak di RS Bhayangkara Manado periode tahun 2013 disimpulkan bahwa kejadian kasus kekerasan pada anak terbanyak terdapat di Kota Manado. Korban terbanyak ialah anak perempuan, jenis kekerasan terbanyak ialah penganiayaan, dan lokasi cedera pada tubuh yang tersering ialah pada bagian kepala anak, terutama mata kiri.

\section{SARAN}

Pola cedera akibat kekerasan pada anak perlu mendapat perhatian mengingat kecacatan yang dapat terjadi akibat cedera tersebut. Diperlukan tim khusus yang menangani kekerasan pada anak mengingat berbagai akibat yang dapat berdampak buruk baik terhadap fisik maupun kejiwaan anak.

\section{DAFTAR PUSTAKA}

1. Anak korban kekerasan (fisik dan mental) dan perlakuan salah (Child abuse) [homepage on the internet]. No date [cited 2014 Sep 12]. Available from: http//www.storage.jakstik.ac.id/Produk Hukum/MenPAN/index.php-option= com_docman\&task=doc_download\&gi $\mathrm{d}=283 \&$ Itemid=116.pdf

2. Solihin L. Tindakan kekerasan pada anak dalam keluarga. Jurnal Pendidikan Penabur. 2004;3:130.

3. Satyo AC. Aspek medikolegal luka pada forensik klinik. Medan: Majalah Kedokteran Nusantara. 2006;39:430-2.

4. Rekam Medis tahun 2013 RS Bhayangkara Manado. 
5. Harian Metro Rabu 11 Maret 2015. Pelecehan seksual anak marak di Sangihe. Manado, 2105: p. 20.

6. Kasus kekerasan terhadap anak di Malaysia mengkhawatirkan [homepage on the internet]. [update 2013 Ags 19; cited 2014 Feb 22]. Available from: http//www.batamtoday.com/berita3215 2-Kasus-Kekerasan-Terhadap-Anak-diMalaysia-Mengkhawatirkan.html

7. Hifema [homepage on the internet]. [update 2013 Jan 17; cited 2014 Feb 23]. Available from: http//www.medicinesia.com/kedokteran -dasar/penginderaan-kedokterandasar/hifema/

8. Katarak traumatika [homepage on the internet]. [update 2012 Sep 10; cited 2014 Feb 23]. Available from: http//lanugojaya.blogspot.com/2012/09/ katarak-traumatika_10.html?m=1

9. Kontrasepsi darurat (KONDAR) [homepage on the internet]. Nodate [cited $2014 \mathrm{Feb}$ 23]. Available from: http//med.unhas. ac.id/obgin/?p=108

10. Roosa MW, Reinholtz C, Angelini PJ. The relation of child sexual abuse and depression in young women: comparisons across four ethnic groups. Journal of Abnormal Child Pshycology. 1999;27(1):56-7.

11. Wisdom CS. Post traumatic stress disorder in abused and neglected children grown up. The American Journal of Psychiatry. 1999;156(8):1223-9.

12. Levitan RD, Rector NA, Sheldon $T$, Goering P. Childhood adversities associated with major depression and/or anxiety disorders in a community sample of Ontario: issues of comorbidity and specificity. Depression and anxiety. 2003; 17(1): 34-42.

13. Messman-Moore TL, Long PJ. Child sexual abuse and revictimization in the form of adult sexual abuse, adult physical abuse, and adult psychological maltreatment. Journal of Interpersonal Violence. 2000;15:489.

14. Dinwiddie S, Health AC, Dunne MP. Early sexual abuse and lifetime psychopathology: a co-twin-control study. Psychological Medicine. 2000;30(1):41-52.

15. Courtois CA. Healing the incest wound: adult survivors in therapy. New York: Norton, 1988; p. 208.

16. Whealin J. Child sexual abuse. National Center for Post Traumatic Stress Disorder. US Department of Veterans Affairs, May 2007.

17. Finkelhor D. Current information on the scope and nature of child sexual abuse. The Future of Children. 1994;4(2):31-53.

18. Gorey KM, Leslie DR. The prevalence of child sexual abuse: integrative review adjustment for potential response and measurement biases. Child Abuse \& Neglect. 1997;21(4):391-8.

19. Dube SR, Anda RF, Whitfield CL, et al. Long-term consequences of childhood sexual abuse by gender of victim. American Journal of Preventive Medicine. 2005;28(5):430-8. 